ORIGINAL ARTICLE

\title{
COVID- I9-related acute kidney injury and dialysis: What are the outcomes in South Africa?
}

\author{
Wesley van Hougenhouck-Tulleken', Muhammed Hussain², Claudia do Vale ${ }^{3}$ \\ 'Steve Biko Academic and Netcare Jakaranda Hospitals, Pretoria, South Africa; '2Lenmed Ahmed Kathrada Private Hospital, \\ Johannesburg, South Africa; ${ }^{3}$ Mediclinic Morningside Hospital, Johannesburg, South Africa.
}

\section{ABSTRACT}

Introduction: Acute kidney injury (AKI) in hospitalized patients infected with COVID-19 is associated with an elevated mortality rate compared to non-infected patients (39\% versus 24\%). This is despite a lower prevalence of AKI in COVID-19-infected patients (I7 vs 22\%). The reasons are multifactorial and have been well documented in developed countries, whereas in developing countries there are scant data.

Methods: This study aimed to document the mortality in COVID-19-infected South African patients who required dialysis for AKI. Exclusion criteria included any chronic kidney replacement therapy (transplantation or dialysis). A REDCap survey of South African nephrologists and nephrology fellows registered with the South African Nephrology Society was conducted. The primary outcome was all-cause in-hospital mortality, while additional points of interest included comorbidities, dialysis modality and intervention required. Univariate analysis of mortality predictors was performed.

Results: The COVID-19-related AKI mortality rate was 58.9\%. Significant predictors included continuous venovenous haemodialysis therapy, invasive ventilation, use of inotropes and the presence of shock. Ischaemic heart disease, heart failure and admission to a private healthcare facility were associated with lower mortality. No significant associations were found with ethnicity, sex, hypertension, diabetes, HIV infection or the use of other modes of dialysis.

Conclusions: In South African patients, we report similar outcomes in critically ill patients requiring dialysis for AKI, relative to international data. The predictors of mortality most likely reflect the severity of the illness in our patients. The data suggest that continuous veno-venous haemodiafiltration or slow low efficiency dialysis may be the preferred dialysis modalities in these patients.

Keywords: COVID-19; acute kidney injury; haemodialysis; South Africa.

\section{INTRODUCTION}

Acute kidney injury (AKI) is a common complication of COVID-19 infection, with 17\% of hospitalized patients developing the condition. While the majority of AKI episodes appear minor ( $50 \%$ of $\mathrm{AKI}$ is at stage I), its presence can increase the patient's mortality risk 15-fold or more [1-3]. Surprisingly, the incidence of COVID-19related $\mathrm{AKI}(17 \%)$ is lower than the documented incidence of pre-COVID-19 AKI of 22\% [4]. This contrasts with the mortality rate, where the AKI-related mortality pre-COVID-19 was 24\%, whereas COVID-19 AKI- related mortality is 39\%, and increased to $53 \%$ for patients requiring continuous renal replacement therapy or ICU admission [2,4].

The aetiology of AKI associated with COVID-I 9 infection is complex, with multiple mechanisms thought to explain the renal injury seen. First, direct toxicity to the kidney is postulated, with a direct viral tropism for the kidneys noted, especially the proximal tubular cells and podocytes $[5,6]$. This is compounded by the cytokine release

Received 08 March 202I; accepted 08 September 202 I; published 28 September 2021 
syndrome (CRS), resulting in both intrarenal inflammation and endothelial dysfunction, aggravating any existing renal injury [6-9]. Second, dysfunction of multiple organ systems can predispose to AKI, including type I cardiorenal syndrome from viral myocarditis, renal medullary hypoxia from acute respiratory distress syndrome and pre-renal failure from shock (hypovolaemic and septic). Third, the presence of a hypercoagulable state in COVID- 19 infection may cause intrarenal ischaemia, predisposing to AKI [I0]. Lastly, renal dysfunction can be iatrogenic, resulting from nephrotoxic agents or renal compartment syndrome from vasopressors, aggressive volume expansion and high peak airway pressures. Considering the above, the presence of AKI in a COVID-19-infected patient may herald the dysfunction of multiple organ systems. This probably accounts for the unusually high mortality seen in patients with COVID-19-related AKI.

Data and observations from countries affected early in the COVID-19 pandemic pointed to a shortage of healthcare resources to manage the increasing number of infected patients [I I]. In particular, a shortage of ICU beds and a lack of capacity for renal replacement therapy were exposed in many developed countries [12]. In South Africa, a developing country, a utilitarian philosophy (the greatest good for the greatest number) was adopted and guidelines rationing the use of ICU beds were established [I3]. Initial evidence underpinning these guidelines, especially in relation to AKI, were extrapolated from outcomes of earlier coronavirus pandemics, namely SARS and MERS [14]. Furthermore, very little evidence is available to guide the clinician as to which dialysis modality to adopt for COVID-19-infected patients with AKI. Ronco et al. acknowledges this, but advocates for high cut-off membranes with continuous veno-venous haemodialysis (CVVHD) to increase cytokine removal $[6,9]$. However, mortality in this patient group, even with CVHD, is still above 50\% [2].

Considering the above, we conducted a nationwide survey of nephrologists in South Africa, in order to define the COVID-19-related AKI mortality rate during the first COVID- 19 wave, and establish which modality of dialysis was associated with the best outcomes.

\section{METHODS}

An anonymous online survey was conducted using a REDCap database hosted at the University of Pretoria [15]. The survey was distributed to all 142 nephrologists and trainee nephrologists registered with the South African Nephrology Society during the first COVID-19 wave (May to September 2020). All data were entered online by the treating nephrologist.
We included COVID-19-infected patients diagnosed with AKI, who required dialysis. Patients already on chronic kidney replacement therapy were excluded. Demographic data, comorbidities, dialysis modality, ventilation and inotrope requirements were recorded. The outcome of interest was all-cause, in-hospital mortality.

The data were exported from REDCap and analysed using SPSS (version 27) and MedCalc (version 19.5.2) [16,17]. Categorical data were summarized with frequencies, whereas continuous data were summarized with means and standard deviations. Odds ratios were calculated for the categorical data, using mortality as the outcome. A P value of 0.05 or less was considered significant.

Ethical approval for the study was granted by the University of Pretoria Human Research Ethics Committee (certificate 308/2020) and approval was also obtained from the South African Nephrology Society.

\section{RESULTS}

At the completion of the study, 142 responses were received. Of these, 52 (37\%) were not considered due to incomplete data or inadequate informed consent, resulting in 90 responses (63\%) being available for analysis. All patients were diagnosed with COVID-19 infection and were in hospital. Although all patients were hospitalized, their level of care was not documented. Table I summarizes the patient characteristics. Of the 90 responses analysed, 45 (50\%) were from the private sector, representing 20 hospitals, compared to 45 (50\%) responses from the public sector, representing three hospitals. Of the 90 responses received, 78 (87\%) were obtained from two provinces (Gauteng and Western Cape). Our data revealed a crude mortality rate of $58.9 \%$, with a rate of $68.8 \%$ in females and $53.5 \%$ in males. Black patients represented the majority of the data (61\%), followed by Whites (18\%).

The univariable analysis of the association of potential risk factors with mortality is summarized in Table 2. Mortality was significantly increased in patients who received inotropes (odds ratio (OR) 5.32), were diagnosed with shock (OR 4.29), required ventilation (OR 6.90) or who resided in the Western Cape (OR 3.17). Patients receiving care in the private sector had a lower mortality rate (OR 0.37 ). Regarding the different dialysis modalities, the use of intermittent haemodialysis was protective (OR 0.13 ), slow low efficiency dialysis (SLED) and continuous veno-venous haemodiafiltration (CVVHDF) had a neutral effect, and CVVHD was associated with higher mortality (OR 19.1). Among the comorbidities, there were no significant associations except for ischaemic heart disease (IHD) (OR $0.12)$ and heart failure (OR 0.15), which were associated with lower mortality. 
Table I. Socio-demographic characteristics of the participants $(n=96)$.

\begin{tabular}{|c|c|c|c|c|}
\hline & & \multicolumn{3}{|c|}{ Died } \\
\hline & & Yes (\%) & No (\%) & Total \\
\hline & Total & $53(58.9)$ & $37(4 I . I)$ & 90 \\
\hline \multirow[t]{8}{*}{ Demographic factors } & Mean age $( \pm S D)$ & $57.5( \pm \mid 4.9)$ & $53.2( \pm 16.7)$ & \\
\hline & Female & $22(68.8)$ & $10(31.3)$ & 32 \\
\hline & Male & $31(53.5)$ & $27(46.6)$ & 58 \\
\hline & Asian & I (100.0) & $0(0.0)$ & । \\
\hline & Black & $32(58.2)$ & $23(41.8)$ & 55 \\
\hline & Mixed & $7(87.5)$ & I (I2.5) & 8 \\
\hline & Indian & $4(50.0)$ & $4(50.0)$ & 8 \\
\hline & White & $8(50.0)$ & $8(50.0)$ & 16 \\
\hline \multirow[t]{2}{*}{ Sector } & Public & $32(71.1)$ & $13(28.9)$ & 45 \\
\hline & Private & $21(46.8)$ & $24(53.3)$ & 45 \\
\hline \multirow[t]{9}{*}{ Province } & Eastern Cape & $5(62.5)$ & $3(37.5)$ & 8 \\
\hline & Free State & $0(0.0)$ & $0(0.0)$ & 0 \\
\hline & Gauteng & $26(50.0)$ & $26(50.0)$ & 52 \\
\hline & KwaZulu-Natal & $0(0.0)$ & I (I00.0) & I \\
\hline & Limpopo & $2(100.0)$ & $0(0.0)$ & 2 \\
\hline & Mpumalanga & $0(0.0)$ & $0(0.0)$ & 0 \\
\hline & Northern Cape & $0(0.0)$ & $0(0.0)$ & 0 \\
\hline & North West & $0(0.0)$ & I (I00.0) & I \\
\hline & Western Cape & $20(76.9)$ & $6(23.1)$ & 26 \\
\hline \multirow[t]{11}{*}{ Comorbidities } & Heart failure & $2(20.0)$ & $8(80.0)$ & 10 \\
\hline & Ischaemic heart disease & $2(18.2)$ & $9(81.8)$ & 11 \\
\hline & Hypertension & $27(55.1)$ & $22(44.9)$ & 49 \\
\hline & Type I diabetes & $0(0.0)$ & I (I00.0) & । \\
\hline & Type 2 diabetes & $21(67.7)$ & $10(32.3)$ & 31 \\
\hline & All diabetes & $21(65.6)$ & II (34.4) & 32 \\
\hline & Metabolic syndrome & $14(66.7)$ & $7(33.3)$ & 21 \\
\hline & $\mathrm{HIV}+\left(\mathrm{CD} 4\right.$ count $>250$ cells $\left./ \mathrm{mm}^{3}\right)$ & $6(42.9)$ & $8(57.1)$ & 14 \\
\hline & $\mathrm{HIV}+\left(\mathrm{CD} 4\right.$ count $<250$ cells $\left./ \mathrm{mm}^{3}\right)$ & $3(42.9)$ & $4(57.1)$ & 7 \\
\hline & All HIV+ & $9(42.9)$ & $12(57.1)$ & 21 \\
\hline & COPD & $2(66.7)$ & I (33.3) & 3 \\
\hline \multirow[t]{5}{*}{ Complications } & ARDS & $28(66.7)$ & $14(33.3)$ & 42 \\
\hline & DIC & $10(62.5)$ & $6(37.5)$ & 16 \\
\hline & Myocarditis & $6(66.7)$ & $3(33.3)$ & 9 \\
\hline & Sepsis & $14(60.9)$ & $9(39.1)$ & 23 \\
\hline & Shock & $27(79.4)$ & $7(20.6)$ & 34 \\
\hline \multirow[t]{7}{*}{ Interventions } & Inotropes & $37(77.1)$ & II (22.9) & 48 \\
\hline & Ventilation & $43(75.4)$ & $14(24.6)$ & 57 \\
\hline & Intermittent HD & $7(25.9)$ & $20(74.1)$ & 27 \\
\hline & SLED & $8(47.1)$ & $9(52.9)$ & 17 \\
\hline & CVVHD & $19(95.0)$ & I (5.0) & 20 \\
\hline & CVHDF & I5 (65.2) & $8(34.8)$ & 23 \\
\hline & CVVHD and CVVHDF & $34(79.1)$ & $9(20.9)$ & 43 \\
\hline
\end{tabular}

Abbreviations: SD, standard deviation; HIV+, patient infected with the human immunodeficiency virus; COPD, chronic obstructive pulmonary disease; ARDS, acute respiratory distress syndrome; DIC, disseminated intravascular coagulopathy; HD, haemodialysis; SLED, slow low efficiency dialysis; CVVHD, continuous veno-venous haemodialysis; CVVHDF, continuous veno-venous haemodiafiltration.

\section{DISCUSSION}

This study assessed the outcomes of AKI in hospitalized South Africans infected with COVID-19 during the first wave of these infections, and to identify risk factors for their mortality. During this period (May to September 2020), the National Institute for Communicable Diseases recorded 259,834 cases of COVID-19 infections in South Africa [18]. Conducted over the same period, our study reported a mortality rate of $58.9 \%$, which was not signi-

ficantly different from other, international COVID- I 9 ICU mortality data (53\%) but was significantly higher than mortality reported in other in-hospital studies (39\%). This suggests that the patients observed in our study had a higher burden of disease and most likely required intensive care. This is corroborated by the high requirement for dialysis (83\%), ventilation (63\%) and inotropes (53\%). Interestingly, continuous dialysis modalities were used more commonly than the prevalence of shock ( $48 \%$ vs $38 \%$, respectively). The reason for this is unclear, but may represent attempts by the treating nephrologists to 
Table 2. Univariable analysis of the association of potential risk factors with mortality.

\begin{tabular}{|c|c|c|c|c|}
\hline & & Odds ratio & $\begin{array}{l}\text { 95\% Confidence } \\
\text { interval }\end{array}$ & $\mathrm{P}$ \\
\hline \multirow[t]{7}{*}{ Demographic factors } & Western Cape province vs Gauteng & 3.17 & $1.05-9.59$ & 0.03 \\
\hline & Other provinces vs Gauteng & 1.40 & $0.39-5.05$ & 0.61 \\
\hline & Private vs public sector & 0.37 & $0.15-0.91$ & 0.02 \\
\hline & Male vs female sex & 0.51 & $0.20-1.28$ & 0.14 \\
\hline & Mixed ancestry vs Black & 5.03 & $0.54-46.58$ & 0.11 \\
\hline & Indian vs Black & 0.72 & $0.16-3.22$ & 0.66 \\
\hline & White vs Black & 0.72 & $0.23-2.22$ & 0.56 \\
\hline \multirow[t]{9}{*}{ Comorbidities } & Heart failure & 0.15 & $0.03-0.79$ & 0.01 \\
\hline & Ischaemic heart disease & 0.12 & $0.02-0.68$ & $<0.01$ \\
\hline & Hypertension & 0.74 & $0.31-1.74$ & 0.48 \\
\hline & Diabetes mellitus & 1.60 & $0.65-3.97$ & 0.30 \\
\hline & Metabolic syndrome & 1.58 & $0.56-4.45$ & 0.38 \\
\hline & $\mathrm{HIV}+\left(\mathrm{CD} 4\right.$ count $>250$ cells $\left./ \mathrm{mm}^{3}\right)$ & 0.47 & $0.15-1.53$ & 0.20 \\
\hline & $\mathrm{HIV}+(\mathrm{CD} 4$ count $>250$ cells/mm³) & 0.51 & $0.10-2.44$ & 0.39 \\
\hline & All HIV+ & 0.44 & $0.16-1.20$ & 0.10 \\
\hline & COPD & 1.44 & $0.12-16.74$ & 0.77 \\
\hline \multirow[t]{5}{*}{ Complications } & ARDS & 1.77 & $0.74-4.24$ & 0.19 \\
\hline & DIC & 1.23 & $0.40-3.77$ & 0.72 \\
\hline & Myocarditis & 1.48 & $0.34-6.40$ & 0.60 \\
\hline & Sepsis & 1.15 & $0.43-3.04$ & 0.78 \\
\hline & Shock & 4.29 & $1.51-12.19$ & $<0.01$ \\
\hline \multirow[t]{7}{*}{ Interventions } & Inotropes & 5.32 & $1.95-14.50$ & $<0.01$ \\
\hline & Ventilated & 6.90 & $2.36-20.14$ & $<0.01$ \\
\hline & Intermittent HD & 0.13 & $0.042-0.42$ & $<0.01$ \\
\hline & SLEDD & 0.57 & $0.19-1.66$ & 0.29 \\
\hline & CVVHD & 19.06 & $2.01-181.13$ & $<0.01$ \\
\hline & CVVHDF & 1.47 & $0.54-3.98$ & 0.45 \\
\hline & Any CVVHD & 5.40 & $1.94-15.05$ & $<0.01$ \\
\hline
\end{tabular}

Abbreviations: $\mathrm{HIV}+$, patient infected with the human immunodeficiency virus; COPD, chronic obstructive pulmonary disease; ARDS, acute respiratory distress syndrome; DIC, disseminated intravascular coagulopathy; HD, haemodialysis; SLED, slow low efficiency dialysis; CVVHD, continuous veno-venous haemodialysis; CVHDF, continuous veno-venous haemodiafiltration.

increase the clearance of the inflammatory cytokines seen during the COVID-19 CRS [6].

The significant predictors of mortality-shock, mechanical ventilation, continuous dialysis therapies or inotropes-in this study most likely represent the critical illness suffered by these patients. However, as COVID-19-related AKI likely heralds the dysfunction of multiple organ systems, the presence of AKI in an otherwise stable COVID- 19-infected patient should prompt the clinician to initiate aggressive therapy sooner rather than later. This approach can be justified by the fact that mortality increases 15-fold in COVID- I9-infected patients with AKI [I].

A surprising finding from our study was that intermittent haemodialysis was a significant predictor of patient survival. The current opinion that continuous high cut-off dialytic therapies are superior due to increased clearance of COVID-19 CRS inflammatory cytokines goes against this $[6,9]$. The theoretical benefit of high cut-off continuous therapies, however, may not be the only reason they are therapies may be used in haemodynamically unstable patients, whereas intermittent therapies are used for stable patients. We suspect that this may have occurred in our study, and thus introduced a bias favouring intermittent haemodialysis. However, the possibility of high cut-off dialytic therapies being beneficial in COVID-19 AKI is still appealing. On further analysis of our data, we found that CVVHDF had a neutral mortality effect, whereas CVVHD was the greatest mortality predictor. This suggests that CVVHDF may be the better choice of dialysis in critically ill COVID-19 patients, presumably due to removal of CRS cytokines. Overall, we noted a protective effect with intermittent haemodialysis, a neutral effect with SLED and CVVHDF, and a significant increase in mortality with CVVHD. Our data suggest that the treating nephrologist should take a pragmatic approach, opting for CVVHDF or SLED (but not CVVHD) in clinically unstable patients or those diagnosed with severe CRS, while intermittent therapies are reserved for stable patients with mild to moderate COVID-19 infection with no CRS.

Our finding that $I H D$ and heart failure are significant protective factors against mortality is difficult to explain, 
especially as cardiovascular disease is considered a mortality risk factor for COVID-19 infection [9,20]. While the small sample size and incomplete responses likely played a role, we also suspect underreporting in our study, especially regarding $I H D$, as the prevalence in this study was $12 \%$, whereas other studies report IHD at 20-25\% [19].

An important finding of this study is that COVID- 19-related AKI mortality in the South African private sector is significantly lower than that of the public (state) sector (OR $0.37, P=0.02$ ). A major contributor to this is that South Africa's public sector is markedly under-resourced, having limited dialysis services available, and with poor access to the more expensive dialysis modalities such as CVVHDF [20]. We hope that the introduction of the National Health Insurance scheme by the South African government will begin to address this issue [2I].

This study was limited by a number of factors. The study design was an anonymous online survey, which did not allow us to determine the response rate, and thus we cannot fully assess the representativeness of our samples. We suspect underreporting, based on the number of responses received. Additionally, there was no representation from three of the nine provinces in South Africa. Another limitation was that we targeted only nephrologists, and only severe AKI was reported in this survey. Lastly, we were unable to report on the cross-over of patients to intermittent haemodialysis; many who survived CRRT were likely to be converted to intermittent haemodialysis as their condition stabilised.

In conclusion, our study reports the outcomes of AKI in patients with COVID-19 infection in South Africa. We found that COVID-19-related AKI has a similar outcome in South Africa as in other countries. Our data support the use of CVVHDF over CVVHD, but this must be tempered by the availability and cost of these modalities. Of note, SLED was equivalent to CVVHDF. Lastly, while the data suggest that intermittent haemodialysis is protective, this is likely due to nephrologists opting to use this modality in the less ill, haemodynamically stable patients.

\section{REFERENCES}

I. Robbins-Juarez SY, Qian L, King KL, Stevens JS, Husain SA, Radhakrishnan J, et al. Outcomes for patients with COVID-I9 and acute kidney injury: A systematic review and meta-analysis. Kidney Int Rep. 2020; 5(8): I I 49- I I 60.

2. Fominskiy E V., Scandroglio AM, Monti G, Calabrò MG, Landoni G, Dell'Acqua $A$, et al. Prevalence, characteristics, risk factors, and outcomes of invasively ventilated COVID- 19 patients with acute kidney injury and renal replacement therapy. Blood Purif. 2020; 50:102-109.

3. Levin A, Stevens PE, Bilous RW, Coresh J, De Francisco ALM, De Jong PE, et al. Kidney Disease: Improving Global Outcomes
(KDIGO) CKD work group. KDIGO 2012 clinical practice guideline for the evaluation and management of chronic kidney disease. Kidney Int Suppl. 2013; 3:I - 150.

4. Susantitaphong P, Cruz DN, Cerda J, Abulfaraj M, Alqahtani F, Koulouridis I, et al. World incidence of AKI: A meta-analysis. Clin J Am Soc Nephrol. 2013; 8(9): | 482-I 493.

5. Puelles VG, Lütgehetmann M, Lindenmeyer MT, Sperhake JP, Wong $\mathrm{MN}$, Allweiss L, et al. Multiorgan and renal tropism of SARS-CoV-2. N Engl J Med. 2020; 383:590-592.

6. Ronco C, Reis T. Kidney involvement in COVID-19 and rationale for extracorporeal therapies. Nat Rev Nephrol. 2020; 16:308-310.

7. Apetrii M, Enache S, Siriopol D, Burlacu A, Kanbay A, Kanbay M, et al. A brand-new cardiorenal syndrome in the COVID-19 setting. Clin Kidney J. 2020; 13:291-296.

8. Panitchote A, Mehkri O, Hasting A, Hanane T, Demirjian S, Torbic H, et al. Factors associated with acute kidney injury in acute respiratory distress syndrome. Ann Intensive Care. 2019; 9:I-10.

9. Elsayed HM, Wadee S, Zaki MS, Were AJ, Ashuntantang GE, Bamgboye EL, et al. Guidelines for the prevention, detection and management of the renal complications of COVID-19 in Africa. Afr J Nephrol. 2020; 23: I09- 126.

10. Su H, Yang M, Wan C, Yi LX, Tang F, Zhu HY, et al. Renal histopathological analysis of 26 postmortem findings of patients with COVID-19 in China. Kidney Int. 2020; 98:219-227.

I I. Senni M. COVID- 19 experience in Bergamo, Italy. Eur Heart J. 2020; 41:1783-1784.

12. Goldfarb DS, Benstein JA, Zhdanova O, Hammer E, Block CA, Caplin NJ, et al. Impending shortages of kidney replacement therapy for COVID-19 patients. Clin J Am Soc Nephrol. 2020; 15:880-882.

13. Gopalan P, Joubert I, Paruk F, Baker D, Coetzee I, de Vasconcellos K, et al. The Critical Care Society of Southern Africa guidelines on the allocation of scarce critical care resources during the COVID-19 public health emergency in South Africa. S Afr Med J. 2020; I I0(8):700-703.

14. Chu KH, Tsang WK, Tang CS, Lam MF, Lai FM, To KF, et al. Acute renal impairment in coronavirus-associated severe acute respiratory syndrome. Kidney Int. 2005; 67:698-705.

I5. Harris PA, Taylor R, Thielke R, Payne J, Gonzalez N, Conde JG. Research electronic data capture (REDCap)-A metadata-driven methodology and workflow process for providing translational research informatics support. J Biomed Inform. 2009; 42:377-38I.

16. IBM SPSS Statistics for Windows version 27. Armonk, NY: IBM Corporation; 2020.

17. MedCalc Statistical Software version 19.5.2. MedCalc Software Ltd, Ostend, Belgium; 2020.

18. Cohen C. An update on COVID-19 outbreak in South Africa The first and the second wave of COVID-19 cases in South Africa, January 2021. Commun Dis Commun. 2021; 20(I):6-8.

19. Nishiga M, Wang DW, Han Y, Lewis DB, Wu JC. COVID-19 and cardiovascular disease: from basic mechanisms to clinical perspective. Nat Rev Cardiol. 2020; 17:543-558.

20. Davids MR, Jardine T, Marais N, Zunza M, Jacobs JC, Sebastian S. South African Renal Registry Annual Report 2017. Afr J Nephrol. 2019; 22:60-71.

21. National Health Insurance. South African Department of Health. http://www.health.gov.za/nhi/. Accessed 14 October 2020. 